\title{
Exogenous Progesterone Attenuates the Subjective Effects of Smoked Cocaine in Women, but not in Men
}

\author{
Suzette M Evans*, I and Richard W Foltin' \\ 'New York State Psychiatric Institute and Department of Psychiatry, College of Physicians and Surgeons of Columbia University, New York, \\ NY, USA
}

\begin{abstract}
In a previous study, we showed that the positive subjective effects of cocaine were higher during the follicular phase compared to the luteal phase of the menstrual cycle. The purpose of the present study was to determine if exogenously administered progesterone during the follicular phase in females would attenuate the response to cocaine compared to the normal follicular phase, thus making the response to cocaine similar to the luteal phase. To address the role of sex differences, males were also administered exogenous progesterone during one inpatient stay. In all, II female and 10 male non-treatment-seeking cocaine smokers participated. Females had three inpatient stays: one during a normal follicular phase, one during a normal luteal phase, and one during a follicular phase when exogenous progesterone was administered. Males had two inpatient stays: one when exogenous progesterone was administered and the other when placebo was administered. During each inpatient admission, there were four smoked cocaine administration sessions: participants were administered six doses of cocaine $(0,6,12$, or $25 \mathrm{mg}$ cocaine base) at 14 min intervals. Smoked cocaine increased heart rate, blood pressure and several subjective effects such as 'good drug effect' and 'drug quality' cluster scores. Administration of progesterone during the follicular phase in women attenuated the positive subjective effects of cocaine, whereas only minimal changes were observed in men. These results indicate that progesterone modulates the response to cocaine in women and suggests that fluctuations in endogenous progesterone levels account for some of the sex differences observed in humans.

Neuropsychopharmacology (2006) 3 I, 659-674. doi:I0.1038/sj.npp. I300887; published online 7 September 2005
\end{abstract}

Keywords: cocaine; humans; sex differences; menstrual cycle; progesterone; subjective effects

\section{INTRODUCTION}

Numerous preclinical studies have documented that female rodents are more sensitive than male rodents to several behavioral effects of stimulant administration (eg Roberts et al, 1989; Sell et al, 2000), and these differences are related to gonadal hormone levels in females (eg Roberts et al, 1987; Grimm and See, 1997; Quiñones-Jenab et al, 1999; also see review by Lynch et al, 2002). Several studies have demonstrated that the greatest increase in behavioral activity when stimulants are administered to female rodents occurs during estrus compared to other phases of the estrous cycle (Becker et al, 1982; Becker and Cha, 1989; Diaz-Veliz et al, 1994; Quiñones-Jenab et al, 1999; Sell et al, 2000). For example, during estrus, female rats (1) have higher progressive ratio breakpoints for cocaine selfadministration (Roberts et al, 1989; Hecht et al, 1999), (2)

\footnotetext{
*Correspondence: Dr SM Evans, New York State Psychiatric Institute and Department of Psychiatry, College of Physicians and Surgeons of Columbia University, I05I Riverside Drive, Unit 66, New York, NY 10032, USA, Tel: + I 212543 5895, Fax: + I 2125436018

E-mail: se18@columbia.edu

Received 17 March 2005; revised 18 July 2005; accepted 19 July 2005 Online publication: 4 August 2005 at http://www.acnp.org/citations/ Npp080405050 | 86/default.pdf
}

show greater disruptions in the regulation of cocaine selfadministration (Lynch et al, 2000), and (3) select the highest cocaine dose (Lynch et al, 2000). Ovariectomy has been shown to reduce the behavioral effects of stimulants (Becker et al, 1982; Camp et al, 1986; Roberts et al, 1987; Haney et al, 1994; Sircar and Kim, 1999), whereas exogenously administered estradiol has been shown to restore or enhance the behavioral effects of stimulants in ovariectomized female rodents (Castner et al, 1993; Grimm and See, 1997; Sircar and Kim, 1999; Sell et al, 2000; Hu and Becker, 2003), including cocaine self-administration (Lynch et al, 2001; Hu et al, 2004; but see Caine et al, 2004).

Thus, the prevailing evidence in the preclinical literature using laboratory rodents is that the differences in response to stimulants observed between males and females are related primarily to the ovarian hormone estrogen (see reviews by Lynch et al, 2002; Mello and Mendelson, 2002; Carroll et al, 2004; Festa and Quiñones-Jenab, 2004). However, while many of the increases in the reinforcing effects of cocaine are observed during estrus in rodents, both estradiol and progesterone levels are relatively low during estrus (similar to the early follicular phase in human females) and actually peak during proestrus (Butcher et al, 1974; Smith et al, 1975). There is increasing evidence in laboratory animals that progesterone also modulates the 
effects of stimulants, but the findings have been inconsistent. For instance, in one study (Quiñones-Jenab et al, 2000), ovariectomized female rats pretreated with estrogen plus progesterone exhibited a reduction in cocaine-induced locomotor activity compared to female rats pretreated with estrogen alone. In contrast, another study (Sell et al, 2000) showed that ovariectomized female rats pretreated with estrogen or estrogen plus progesterone showed an enhancement in cocaine-induced locomotor activity compared to female rats pretreated with progesterone alone. Further, in a recent study, progesterone administration to ovariectomized female rats blocked the conditioned place preference for cocaine, whereas estrogen plus progesterone administration enhanced the conditioned place preference (Russo et al, 2003).

Sex differences in humans following cocaine administration have generally been more subtle (eg Kosten et al, 1996; Lukas et al, 1996; Evans et al, 1999; Sofuoglu et al, 1999). While Haney et al (1998) showed that human females had a higher progressive ratio breakpoint for intravenous cocaine than males, that study did not address or control for menstrual cycle phase. Among studies in humans that have addressed the role of menstrual cycle phase, several have shown that the positive subjective effects of stimulants are greater during the follicular phase than the luteal phase (Justice and de Wit, 1999; Sofuoglu et al, 1999; Evans et al, 2002; but see Lukas et al, 1996; Mendelson et al, 1999). Therefore, based on the limited human data available, in the presence of estradiol and in the absence of progesterone (ie the follicular phase), the effects of cocaine or amphetamine appear to be increased compared to the luteal phase (characterized by elevated estradiol and progesterone levels). While the data in humans suggest that the increased response to stimulants is due primarily to estradiol, the evidence supporting this is not so straightforward. In one study, Justice and de Wit (1999) found that the increased response to amphetamine was related to estradiol levels in the follicular phase, but not in the luteal phase. However, a subsequent study from the same laboratory (Justice and de Wit, 2000a) found minimal differences in response to amphetamine between the early and late follicular phases of the menstrual cycle, despite significantly higher estradiol levels in the late follicular phase. Further, even high doses of exogenously administered estradiol in the early follicular phase produced minimal changes in the response to amphetamine (Justice and de Wit, 2000b).

There is growing evidence in humans that progesterone may reduce the behavioral effects of stimulants. When compared to males, females in the follicular phase reported a similar increase in positive subjective effects following amphetamine, whereas during the luteal phase the response in females was reduced compared to the follicular phase or to males (White et al, 2002). Similarly, Sofuoglu et al (1999) reported that ratings of 'high' were comparable following smoked cocaine in men and follicular-phase women, but were significantly lower in luteal-phase women compared to follicular-phase women. In a subsequent study conducted only in females (Sofuoglu et al, 2002), oral progesterone attenuated the subjective effects, but not the cardiovascular effects, of smoked cocaine during the follicular phase. Lastly, in a mixed-gender sample, oral progesterone administration attenuated cocaine-induced increases in diastolic blood pressure and several positive subjective effects of cocaine, but did not alter intravenous cocaine selfadministration (Sofuoglu et al, 2004). At this time, it is unclear whether the differential response to stimulants in females is due primarily to estradiol enhancing the effects of stimulants or due primarily to progesterone attenuating the effects of stimulants, or a more complex interaction between the two hormones.

The purpose of the present study was to address the possible mechanism underlying the menstrual cycle differences observed in females in response to cocaine by extending and improving upon the recent findings in humans suggesting that oral progesterone administration reduces the response to cocaine. The strengths of the present study are that (1) a full dose-response function for smoked cocaine $(0,6,12$, and $25 \mathrm{mg}$ cocaine base) was determined; (2) repeated doses of smoked cocaine (six within a session) were administered; (3) females were tested twice in the follicular phase (once in the presence of exogenous progesterone and once during a normal follicular phase) and in the normal midluteal phase of the menstrual cycle; and (4) to address the role of sex differences, males were also administered exogenous progesterone and placebo under the same experimental conditions.

\section{MATERIALS AND METHODS}

\section{Participants}

Eleven female research volunteers (10 African-American and one Hispanic), 27-43 years of age $($ mean $=38)$, and 10 male research volunteers (nine African-American and one Hispanic) 28-42 years of age $($ mean $=37)$, with current histories of smoking cocaine were solicited through newspaper advertisements in New York, NY. Females reported currently spending $\$ 100-1000($ mean $=\$ 443)$ per week on cocaine and using cocaine an average of four days each week. Men reported currently spending $\$ 150-350$ per week on cocaine (mean $=\$ 228)$ and using cocaine an average of 4 days each week. All participants reported smoking tobacco cigarettes, with females smoking an average of nine cigarettes/day and males smoking an average of 12 cigarettes/day. Men and women had similar education levels (mean of 12.5 years for females and 11.9 years for males). Although females were slightly heavier than males, with females having a mean body mass index (BMI) of 28.6 (17-37) and males having a mean BMI of 25.5 (23-28), this was not statistically significant. All participants were medically and psychiatrically healthy based on a physical examination, electrocardiogram, chest X-ray, complete blood chemistries (including pseudocholinesterase levels), urinalyses, and a structured clinical interview to assess DSM-IV Axis I disorders (SCID I; First et al, 1994). None were receiving psychiatric treatment or seeking treatment for their drug use, and none of the participants were using hormonal contraceptives, or any other prescription medication. Also, women were not pregnant (based on blood pregnancy tests) or nursing, and had not had an abortion or been pregnant within the previous 6 months. Lastly, none of the female participants suffered from premenstrual dysphoric disorder. 
Each participant signed a consent form, approved by the Institutional Review Board of The New York State Psychiatric Institute. The consent form described the study, outlined possible risks, and indicated that cocaine would be administered, possibly on a daily basis. Participants were paid for their participation in multiple weekly payments not to exceed a value of $\$ 300$ each week.

\section{Design and Experimental Procedures}

After signing the study consent form, all participants began filling out daily rating forms each evening; they were paid to report to the laboratory twice a week to return completed forms and pick up new forms. For females, this was done to ensure continued outpatient contact in order to monitor the menstrual cycle and schedule the various inpatient phases. The forms asked questions related to various aspects of daily mood and physical symptoms that vary across the menstrual cycle and females indicated whether they were menstruating. Female participants were prospectively tracked for several weeks before the first inpatient admission, and throughout the study, to determine menstrual cycle length and time of ovulation. They were instructed to notify the research nurse when menstruation started. During the midfollicular phase, female participants provided daily urine samples to determine the time of ovulation using OvuQuick ${ }^{\mathbb{R}}$ (QUIDEL Corp., San Diego, CA; Martini et al, 1994). This test is simple to use and is 96-99\% accurate at detecting luteinizing hormone (LH) in urine. The day of ovulation was used to schedule the midluteal admission. To provide consistency, males filled out a comparable daily rating form (excluding questions regarding menses), and where appropriate questions were modified (eg breast tenderness for females became skin tenderness for males).

Participants were admitted to the NIH-funded Irving Center for Clinical Research. While residing on the Clinical Research Center, all participants had access to television, radio, and video-taped movies, but were not permitted to leave the unit unless accompanied by a staff member. Participants who smoked tobacco cigarettes were allowed to smoke throughout their inpatient stay. However, smoking was not allowed during experimental sessions, which lasted approximately $2.5 \mathrm{~h}$ each.

Female participants were admitted to the unit for 4 days (three nights) on three separate occasions. Two inpatient admissions were scheduled during the follicular phase so that cocaine administration sessions occurred between 6-10 days after the onset of menstruation. One follicular phase was normal (elevated estradiol and negligible progesterone levels), and the other follicular phase was designed to mimic a midluteal phase by administering oral micronized progesterone. The third inpatient admission was scheduled during a normal midluteal phase (approximately 7-12 days after the urinary ovulation test kit indicated that ovulation had occurred) characterized by elevated estradiol and progesterone levels. Male participants were admitted to the unit for 4 days (three nights) on two separate occasions, spaced 2-3 weeks apart. Half of the males were administered oral micronized progesterone during the first admission and half were administered placebo during the first admission. For both females and males, the day following each inpatient admission, participants engaged in laboratory sessions twice each day for 2 days and were discharged on the fourth inpatient day.

\section{Progesterone Dosing}

The dose of oral micronized progesterone selected was chosen to produce progesterone levels comparable to those observed during the normal midluteal phase of the menstrual cycle in females. Oral micronized progesterone is commercially available as Premarin ${ }^{\circledR}$ in 100 - or 200 -mg doses. A pharmacokinetic study (Simon et al, 1993) showed that the $100 \mathrm{mg}$ dose produced lower progesterone levels (approximately $6.5 \mathrm{ng} / \mathrm{ml}$ ) and the $200 \mathrm{mg}$ dose produced higher progesterone levels $(13.8 \mathrm{ng} / \mathrm{ml})$ than the normal midluteal levels observed in one of our previous studies (10.0 ng/ml; Evans et al, 2002), suggesting the need for an intermediate dose of $150 \mathrm{mg}$. This was accomplished by having oral micronized progesterone compounded by the Women's International Pharmacy as $50 \mathrm{mg}$ capsules. During each inpatient phase, participants were administered $150 \mathrm{mg}$ oral micronized progesterone or matching placebo capsules at $2300 \mathrm{~h}$ on the evening before the first cocaine session since steady-state levels are reached after the second dose (de Lignieres, 1999). Then, on the next two consecutive days, participants were administered $150 \mathrm{mg}$ oral micronized progesterone or matching placebo capsules at 0700 and $1100 \mathrm{~h}$, approximately $2 \mathrm{~h}$ before each cocaine session, since oral micronized progesterone levels peak in 1-3h (Simon et al, 1993). Even though the mean terminal half-life for doses between $100-300 \mathrm{mg}$ oral micronized progesterone is between 16-18 h (Simon et al, 1993), dosing was done before each session since some studies have shown that progesterone levels can start declining within $4 \mathrm{~h}$ after administration (Maxson and Hargrove, 1985).

\section{Experimental Sessions}

During each inpatient phase, cocaine administration sessions occurred at $0900 \mathrm{~h}$ and again at $1300 \mathrm{~h}$ on two consecutive days, for a total of four sessions. During each session, participants were administered up to six doses of smoked cocaine (either $0,6,12$, or $25 \mathrm{mg}$ cocaine base depending on the session) at 14-min intervals. The dose order within each phase was randomized and the dose order across the phases was not identical for a given individual. During experimental sessions, each participant was seated in a comfortable lounge chair in front of a computer monitor on which subjective-effects questions were displayed. A computer mouse was used for completion of the subjective-effects questionnaires. An 18-gauge catheter (Quik-Cath ${ }^{\circledR}$, Travenol Laboratories, Deerfield, IL) was inserted into a subcutaneous vein in one arm for blood collection. An electrocardiogram was continuously monitored via chest electrodes (MAC PC ${ }^{\circledR}$, Marquette Electronics, Milwaukee, WI), while heart rate and blood pressure were recorded every 2 min (Sentry II-Model 6100 automated vital signs monitor, NBS Medical, Costa Mesa, CA) beginning $20 \mathrm{~min}$ prior to drug administration. A Macintosh computer located in an adjacent room was used for automated data collection. 
Participants were instructed that the purpose of the study was to assess the effects of the hormone progesterone on their response to repeated doses of smoked cocaine; women were also told that we were interested in the effects of cocaine at different phases of their menstrual cycle. This was not a self-administration session, but participants were told that they had the option of refusing a dose. Each cocaine administration session began with $20 \mathrm{~min}$ of baseline vital signs and participants completed the baseline subjective-effects questionnaires at $-10 \mathrm{~min}$. During each session, participants were administered the cocaine dose available that session at 14 min intervals for a total of six doses per session, with the first dose given at time 0 . Volatization of the cocaine base was accomplished by the nurse holding the flame from a pipe lighter on the cocaine in the glass stem. Participants were instructed to take one large inhalation and to hold the inhalation as long as they normally would outside of the laboratory. During the administration of cocaine, participants were blindfolded, so they could not see the size of the cocaine dose. When $0 \mathrm{mg}$ cocaine (placebo) was administered, a flame was applied to an empty glass stem and participants inhaled warm air.

During the session, the subjective-effects questionnaire was repeated $4 \mathrm{~min}$ after the administration of each cocaine dose (even if a dose was refused), as well as $15 \mathrm{~min}$ after the last cocaine dose. Cocaine was not given on any trial that any cardiovascular measure was above our criteria for safe drug administration (systolic pressure $>160$; diastolic pressure $>100$ or a heart rate of $220-$ subject age $\times 0.85$, sustained for more than 6 min prior to the next scheduled dose administration). During all sessions, participants were continuously monitored via a one-way mirror by a research nurse and a physician located in the adjacent room, and participants could communicate with nurses via an intercom system.

During each session, blood was drawn for determination of progesterone and estradiol levels at baseline (before administration of the first cocaine dose each experimental session) to verify progesterone levels and menstrual cycle phase (in females). In addition, blood was drawn for determination of cocaine and metabolite plasma levels at baseline, $4 \mathrm{~min}$ after the first dose, $4 \mathrm{~min}$ after the third dose, and $4 \mathrm{~min}$ after the sixth dose.

\section{Subjective-Effects Questionnaires}

A computerized questionnaire was completed repeatedly during each session: $10 \mathrm{~min}$ before the first cocaine dose, $4 \mathrm{~min}$ after each cocaine dose, and $15 \mathrm{~min}$ after the last cocaine dose. The questionnaire consisted of a series of 100$\mathrm{mm}$ visual analog scales (VAS) labeled 'not at all' $(0 \mathrm{~mm})$ at one end and 'extremely' (100 mm) at the other end. In all, 20 of the VAS items resulted in five clusters. 'Bad drug effect' consisted of seven items related to negative drug effects (eg 'bad drug effect', 'anxious'), 'self-esteem' consisted of five items (eg 'self-confident', 'friendly'), 'calm' consisted of two items ('calm' and 'focused'), 'good drug effect' consisted of three items ('high', 'good drug effect', and 'stimulated'), and 'drug quality' consisted of three items related to the cocaine dose the participant had just received ('drug quality', 'drug potency', and 'drug liking'). Three VAS were used to operationalize drug craving, and were labeled 'I want...',
'... cocaine', '... alcohol', and '... nicotine'. A final question asked the participants 'How much would you pay for the dose you just received?' with a range of $\$ 0-25$.

\section{Drugs}

Cocaine base, derived from cocaine hydrochloride (provided by The National Institute on Drug Abuse) as described in Foltin et al (1990), was prepared by The New York State Psychiatric Institute research pharmacy.

Oral micronized progesterone and matching placebo capsules were generously provided by the Women's International Pharmacy (Madison, WI). Progesterone capsules contained $50 \mathrm{mg}$ each of micronized progesterone suspended in olive oil and the placebo capsules contained lactose suspended in olive oil. Participants were administered three capsules (total of $150 \mathrm{mg}$ ) at each dosing time (described above).

\section{Hormone Assays}

Each experimental day, before cocaine administration, venous blood samples (approximately $6 \mathrm{ml}$ ) for estradiol and progesterone were drawn from an indwelling catheter into tubes containing SST ${ }^{\circledR}$ gel and clot activator. Samples were centrifuged within $30 \mathrm{~min}$ of collection, yielding approximately $3 \mathrm{ml}$ of plasma, and stored frozen until the time of analysis. Estradiol and progesterone levels were determined by Dr Michel Ferin at the College of Physicians and Surgeons of Columbia University, Department of Obstetrics and Gynecology (New York, NY). Estradiol and progesterone were measured by a commercial solid-phase, chemiluminescent immunoassay (Immulite, Diagnostic Products Co., DPC, Los Angeles, CA). For estradiol, the assay sensitivity was $4 \mathrm{pg} / \mathrm{ml}$ and the intra- and interassay coefficients of variation were 4.3 and $10.5 \%$. For progesterone, the assay sensitivity was $0.2 \mathrm{ng} / \mathrm{ml}$ and the intra- and interassay coefficients of variation were 4.8 and $9.1 \%$.

\section{Cocaine Analysis}

Venous blood samples (approximately $6 \mathrm{ml}$ ) for cocaine were drawn from an indwelling catheter into tubes containing potassium oxalate and sodium fluoride. Samples were immediately mixed and placed on ice until they could be centrifuged. They were centrifuged within $30 \mathrm{~min}$ of collection, yielding approximately $3 \mathrm{ml}$ of plasma, and stored frozen until the time of analysis. Blood samples for cocaine were obtained at baseline (before the first cocaine dose), $4 \mathrm{~min}$ after the first dose, $4 \mathrm{~min}$ after the third dose, and $4 \mathrm{~min}$ after the sixth dose. Cocaine, benzoylecgonine (BZE), and ecgonine methyl ester (EME) plasma levels were determined by $\mathrm{Mr}$ Thomas Cooper at the Nathan Kline Institute for Psychiatric Research (Orangeburg, NY). Cocaine, BZE, and EME were analyzed by capillary gas chromatograph-mass spectrometry using deuterated internal standards, positive chemical ionization, and simultaneous ion monitoring. The assay sensitivity was $1 \mathrm{ng} / \mathrm{ml}$ and intra- and interassay coefficients of variation were less than $6 \%$ for all compounds. 


\section{Data Analysis}

Separate, but identical, analyses were conducted for females and males, with the exception that for females there were three phases (follicular, PROG, luteal) and for males there were two phases (placebo, PROG).

Mean heart rate, systolic pressure, and diastolic pressure, averaged across $8 \mathrm{~min}$, were collected beginning $10 \mathrm{~min}$ before the first cocaine dose, 2 min after each cocaine dose, and $15 \mathrm{~min}$ after the last cocaine dose, for a total of eight measurements within a session. Similarly, each VAS was collected eight times within a session. Each cardiovascular measure, the five VAS clusters (described above) and ratings of 'I want cocaine', 'I want alcohol', 'I want nicotine', and 'Willing to Pay' were analyzed separately.

To determine if there were any baseline cardiovascular or subjective differences as a function of phase, two-factor repeated-measures analyses of variance with phase as the first factor and dose $(0,6,12,25 \mathrm{mg})$ as the second factor were conducted using the data collected during each session before cocaine administration. The repeated-dose effects of cocaine (expressed as a change from baseline) within a session were examined using three-factor repeated-measures analyses of variance with phase as the first factor, dose as the second factor, and time (7 time points) as the third factor. For each measure, planned comparisons were conducted for each cocaine dose separately collapsed across the seven time points in females to compare the effects of the follicular phase to the PROG phase and the follicular phase to the luteal phase. For males, similar planned comparisons were conducted for each cocaine dose between the placebo and PROG phases.

Estradiol and progesterone levels were analyzed separately using a two-factor repeated-measures analysis of variance with phase and dose as factors. Cocaine and metabolite (EME and BZE) plasma levels obtained 4 min after the last cocaine dose (essentially representing maximal levels during a session) were analyzed separately using a two-factor repeated-measures analysis of variance with phase and dose as the two factors.

To specifically address sex differences, the follicular and PROG phases in females were compared to the placebo and PROG phases in males. For selected measures, repeatedmeasures ANOVA were conducted as described above, with sex as the between-subject factor.

For all analyses, results were considered statistically significant if $p<0.05$, using Huynh-Feldt corrections where appropriate.

\section{RESULTS}

\section{Hormone Levels}

All women had normal ovulatory menstrual cycles ranging from 24 to 34 days (mean 29 days). Further, the dosing regimen of oral micronized progesterone used in the present study (five doses of $150 \mathrm{mg}$ micronized progesterone over a 3-day period) did not result in a single incidence of breakthrough bleeding, nor did it disrupt normal menstrual cycle function in any of the females. Figure 1 shows mean estradiol and progesterone levels in the normal follicular phase, the PROG phase, and the normal luteal phase. In females, estradiol levels were significantly higher in the luteal phase compared to either the follicular $(p<0.0001$; only $p$-values will be presented for planned comparisons) or PROG phase $(p<0.0001)$, and no differences in estradiol levels between the PROG and follicular phases $(p=0.11)$. There was a phase effect for progesterone levels $(\mathrm{F}(2,10)=16.070, \quad p=0.0007)$, with progesterone levels in the PROG phase $(p<0.0001)$ and the luteal phase $(p<0.0001)$ being significantly higher than in the follicular phase. There were no differences in progesterone levels in the PROG phase $(8.2 \mathrm{ng} / \mathrm{ml})$ compared to the normal luteal phase $(7.4 \mathrm{ng} / \mathrm{ml} ; p=0.12)$.

Figure 1 also shows that males had similar estradiol levels in the placebo and PROG phases $(p=0.41)$, whereas
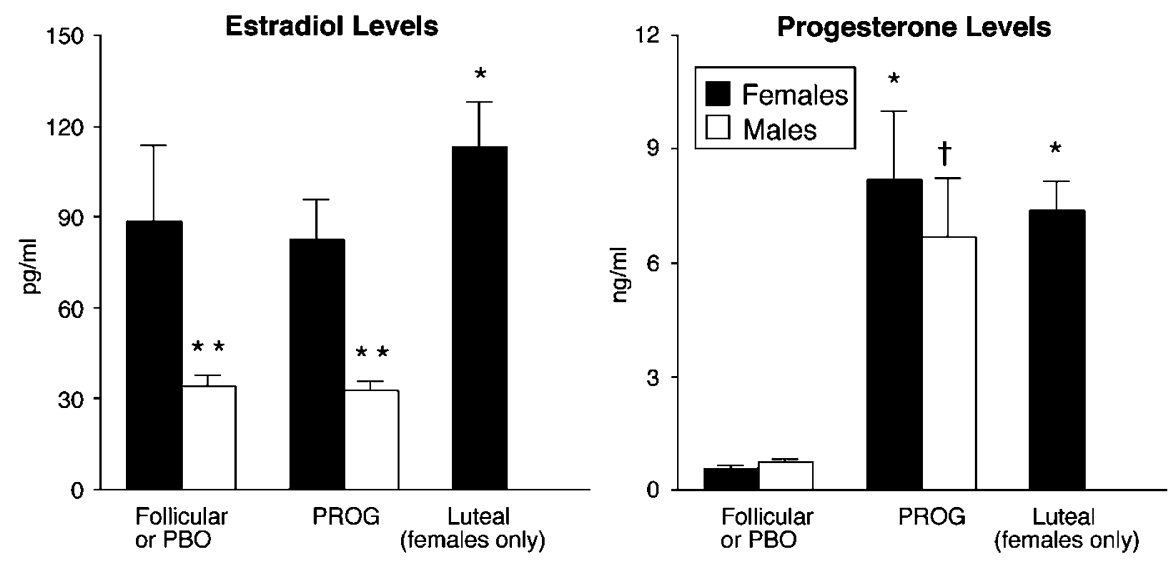

Phase

Figure I Mean estradiol and progesterone plasma levels as a function of study phase and sex. Data points for females show means of II individuals and data points for males show means of 10 individuals; bars represent the mean + I SEM. Females were tested at three menstrual cycle phases: (I) follicular phase when placebo progesterone was administered, (2) PROG (progesterone) phase when progesterone was administered during the follicular phase, and (3) luteal phase when placebo progesterone was administered. Males were tested on two occasions: (I) PBO (placebo) phase and (2) PROG phase. * Indicates a significant difference from the follicular phase in females; ${ }^{*} *$ indicates a significant difference between females and males; ${ }^{\dagger}$ indicates a significant difference from the PBO phase in males. 
progesterone levels showed a phase effect $(\mathrm{F}(1,9)=24.360$, $p=0.0008$ ), with progesterone levels significantly higher in the PROG phase compared to the placebo phase.

When males were compared to females, there was a sex effect $(\mathrm{F}(1,19)=8.193, p=0.01)$ for estradiol levels, with females having significantly higher estradiol levels than males during both the follicular (placebo) and PROG phases. Progesterone levels showed a phase effect $(\mathrm{F}(1,19)=$ 37.990, $p=0.0001)$, with females and males having higher levels of exogenous progesterone in the PROG phase compared to the follicular (placebo) phase. In the PROG phase, males had similar progesterone levels compared to females ( 6.7 and $8.2 \mathrm{ng} / \mathrm{ml}$, respectively).

Table 1 shows the progesterone levels obtained in females during the follicular phase when oral micronized progesterone was administered and during the normal luteal phase as a function of day and time. There were no statistically significant differences in progesterone levels between the follicular phase when exogenous progesterone was administered compared to the normal luteal phase, and there were no differences as a function of day or time in females. However, as shown in Table 1, there was more variability, as indicated by the larger SEM, when oral micronized progesterone was administered compared to the normal luteal phase. Similarly, when oral micronized progesterone was administered to males, there were no differences in progesterone levels as a function of day or time.

\section{Baseline Phase Differences}

The only baseline (ie before cocaine administration) phase difference was on heart rate in females $(\mathrm{F}(2,10)=4.923$, $p=0.0335$ ), with resting heart rate significantly higher in the luteal and PROG phases compared to the follicular phase $(82.3,80.5,75.1 \mathrm{bpm}$; all $p$ 's $<0.04)$.

For males, there were no baseline differences as a function of phase. Further, there were few baseline differences between females and males. Overall, there was a phase effect on heart

Table I Plasma Progesterone Levels $(\mathrm{ng} / \mathrm{ml})$ as a Function of Phase, Day, and Time in Females and Males

\begin{tabular}{lcc}
\hline & Females & Males \\
\hline Exogenous progesterone phase $^{\mathrm{a}}$ & & \\
Day I AM & $7.45( \pm 1.97)$ & $6.49( \pm 1.5 \mathrm{I})$ \\
Day I PM & $8.90( \pm 2.14)$ & $8.70( \pm 2.48)$ \\
Day 2 AM & $8.14( \pm 1.80)$ & $4.31( \pm 0.99)$ \\
Day 2 PM & $8.23( \pm 2.15)$ & \\
& & \\
Luteal phase (females only) & & \\
Day I AM & $7.35( \pm 0.94)$ & \\
Day I PM & $7.44( \pm 0.90)$ & \\
Day 2 AM & $7.76( \pm 0.8 \mathrm{I})$ & \\
Day 2 PM & $6.99( \pm 0.86)$ &
\end{tabular}

a Values represent the mean and \pm I SEM. Blood samples for progesterone levels were drawn approximately $2.5 \mathrm{~h}$ after capsule ingestion. For females, the exogenous progesterone phase was when oral micronized progesterone was administered during the follicular phase. The progesterone levels in the luteal phase for females represent normal endogenous levels. rate $(\mathrm{F}(1,19)=5.808, p=0.0263)$, due to the higher baseline resting heart rate in females during the PROG phase. Also, baseline scores on the self-esteem cluster showed a sex effect $(\mathrm{F}(1,19)=4.269, p=0.0527)$, with females having slightly lower scores than males (58.9 vs 75.4 , respectively).

\section{Cocaine Administration}

During each phase, four cocaine doses were tested $(0,6,12$, and $25 \mathrm{mg}$ ) on separate sessions and during each session a maximum of six cocaine doses could be administered, for a total of 24 possible doses (including placebo) per phase per participant. The 11 females each participated in 3 phases, for a possible total of 792 doses; only a single placebo dose was refused. The 10 males each participated in three phases for a possible total of 480 doses; four placebo doses and two $6 \mathrm{mg}$ doses were refused (all by the same individual). For both females and males, no cocaine doses had to be withheld due to elevated cardiovascular activity.

\section{Cardiovascular Effects of Cocaine}

In females, cocaine produced dose-related increases in systolic pressure $(\mathrm{F}(3,10)=25.697, p=0.0001)$, diastolic pressure $(\mathrm{F}(3,10)=17.871, p=0.0001)$, and heart rate $(\mathrm{F}(3,10)=40.242, p=0.0001)$. Figure 2 (upper left panel) shows that the effects of exogenous progesterone on cocaine-induced increases in diastolic pressure were variable; following $12 \mathrm{mg}$ cocaine, diastolic pressure was increased in the PROG phase $(p<0.001)$, whereas, following $25 \mathrm{mg}$ cocaine, diastolic pressure was decreased in the PROG phase $(p<0.05)$ relative to the follicular phase. Cocaine-induced increases in diastolic pressure were higher in the luteal phase than in the follicular phase following $25 \mathrm{mg}$ cocaine. Figure 2 also shows that the cocaine-induced increases in heart rate (lower left panel) were decreased in the PROG phase following all three cocaine doses $(6 \mathrm{mg}$ : $p<0.001 ; 12 \mathrm{mg}: p<0.001 ; 25 \mathrm{mg}: p<0.0001)$ relative to the follicular phase. The top panels of Figure 3 show the time course function for heart rate as a function of phase and cocaine dose in females. There were no differences in systolic pressure across the three phases (data not shown).

In males, cocaine also produced dose-related increases in systolic pressure $(\mathrm{F}(3,9)=17.564, p=0.0001)$, diastolic pressure $(\mathrm{F}(3,9)=18.936, p=0.0001)$, and heart rate $(\mathrm{F}(3,9)=11.669, p=0.0033)$. Figure 2 (upper right panel) shows that following $6 \mathrm{mg}(p<0.0001)$ and $25 \mathrm{mg}$ cocaine $(p<0.0001)$, diastolic pressure was decreased in the PROG phase compared to the placebo phase. Figure 2 also shows that the cocaine-induced increases in heart rate (lower right panel) were less consistent in males. In the PROG phase, heart rate was increased following $12 \mathrm{mg}$ cocaine $(p<0.01)$, but decreased following $25 \mathrm{mg}$ cocaine $(p<0.0001)$ compared to the placebo phase. The bottom panels of Figure 3 show the time course function for heart rate as a function of phase and cocaine dose in males. There were no differences in systolic pressure between the two phases (data not shown).

\section{Subjective Effects of Cocaine}

The left panels of Figure 4 show that in females, cocaine produced significant dose-related increases on good drug 
Diastolic Pressure
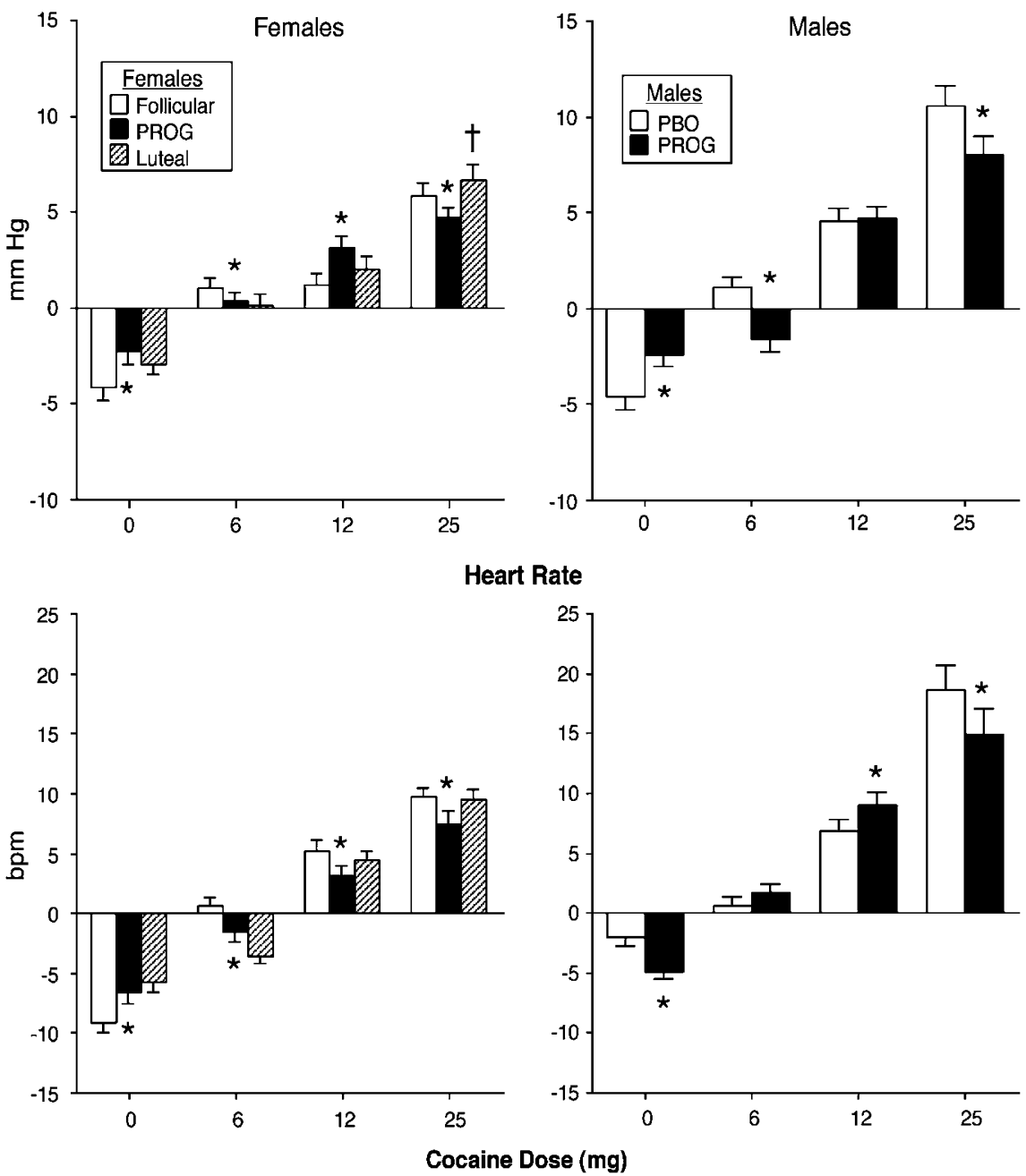

Figure 2 Mean diastolic pressure and heart rate (expressed as change from baseline) as a function of phase and cocaine dose. Each bar represents the mean + I SEM across the repeated administration of cocaine (six) for a given cocaine dose. * Indicates a significant difference between the follicular and PROG phases in females, or a significant difference between the PBO and PROG phases in males at a given cocaine dose condition; ${ }^{\dagger}$ indicates a significant difference between the follicular and luteal phases in females at a given cocaine dose condition. See Figure I for details.

effect cluster scores $(\mathrm{F}(3,10)=16.403, p=0.0006)$, drug quality $(\mathrm{F}(3,10)=13.598, p=0.0015)$ cluster scores, and 'willing to pay' ratings $(\mathrm{F}(3,10)=9.594, p=0.0078)$. There was a phase effect for good drug effect cluster scores $(\mathrm{F}(2,10)=3.580, p=0.0469)$ and a trend for a phase effect for drug quality cluster scores $(\mathrm{F}(2,10)=3.421, p=0.0527)$, with the highest scores observed in the follicular phase, primarily after $25 \mathrm{mg}$ cocaine. Figure 4 also shows that good drug effect cluster scores, drug quality cluster scores, and 'willing to pay' ratings were decreased in the PROG phase following 12 and $25 \mathrm{mg}$ cocaine compared to the follicular phase (all $p$ 's $<0.02$ ). Further, ratings were decreased for all three of these measures in the luteal phase following $25 \mathrm{mg}$ cocaine compared to the follicular phase (all $p$ 's $<0.01$ ). The top panels of Figure 5 show the time course function for good drug effect cluster scores as a function of phase and cocaine dose in females. In contrast, ratings of 'I want cocaine' were not dose-related and there was no consistent phase effect (data not shown). Cocaine also tended to produce dose-related increases on ratings of 'I want nicotine' $(\mathrm{F}(3,10)=3.255, p=0.0594)$, and these ratings were decreased in the PROG phase following $25 \mathrm{mg}$ cocaine $(p<0.0001$; data not shown). Bad drug effect cluster scores were low (less than $7 \mathrm{~mm}$ ); cocaine did not produce doserelated changes in bad drug effect cluster scores, but there was a marginal phase effect $(\mathrm{F}(2,10)=3.399, p=0.0588)$, with scores being lower in the PROG phase compared to the follicular and luteal phases (data not shown).

In males, cocaine produced significant dose-related increases on good drug effect cluster scores $(\mathrm{F}(3,9)=$ 11.643, $p=0.0029)$, drug quality cluster scores $(\mathrm{F}(3,9)=$ $9.575, p=0.0044)$, ratings of 'willing to pay' $(\mathrm{F}(3,9)=5.706$, $p=0.0255)$, 'I want nicotine' $(\mathrm{F}(3,9)=8.302, p=0.0005)$, and marginal increases on ratings of 'I want cocaine' $(\mathrm{F}(3,9)=2.960, p=0.0594)$. The right panels of Figure 4 show that for most cocaine doses, good drug effect, and drug quality cluster scores and ratings of 'willing to pay' were not altered in the PROG phase compared to the placebo phase (except that ratings of 'willing to pay' were decreased in PROG phase following $6 \mathrm{mg}$ ). The bottom 

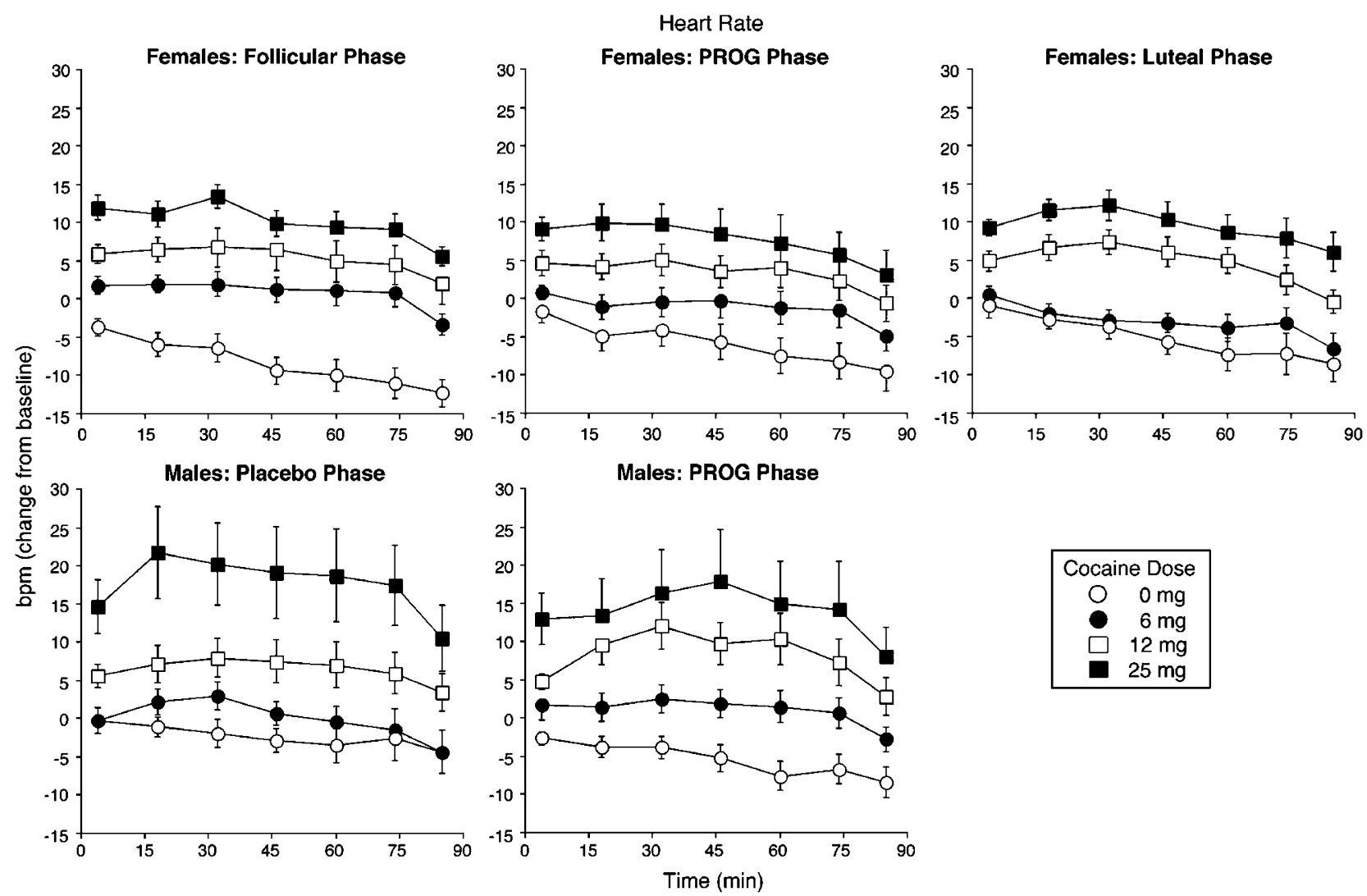

Figure 3 Time course function for heart rate as a function of phase and cocaine dose, expressed as a change from baseline. For females, data from each of the three phases are presented in the top panels and each data point represents the mean \pm I SEM. For males, data from each of the two phases are presented in the bottom panels and each data point represents the mean \pm I SEM.

panels of Figure 5 show the time course function for good drug effect cluster scores as a function of phase and cocaine dose in males. Only ratings of 'I want cocaine' showed a marginal phase effect $(\mathrm{F}(1,9)=3.967, p=0.0776)$, with ratings increased in the PROG phase compared to the placebo phase following 0,6 , and $25 \mathrm{mg}$ (all $p$ 's $<0.03$ ), but decreased following $12 \mathrm{mg}$ cocaine $(p<0.02$; data not shown). Bad drug effect cluster scores showed a dose effect $(\mathrm{F}(3,9)=4.073, p=0.0255)$, but all scores were low (less than $7 \mathrm{~mm}$ ), and there was no effect of phase.

\section{Cocaine and Metabolite Plasma Levels}

In females, cocaine plasma levels $4 \mathrm{~min}$ after the last cocaine dose in each session increased as a function of dose $(F(3,10)=124.382, p=0.0001)$, but there were no differences as a function of phase. Dose-related effects were also observed in females for $\operatorname{EME}(\mathrm{F}(3,10)=47.583$, $p=0.0001)$ and BZE plasma levels $(\mathrm{F}(3,10)=17.993$, $p=0.0001$ ), again there were no differences as a function of phase. Similarly, in males there were dose-related increases in cocaine $(\mathrm{F}(3,9)=87.075, p=0.0001)$, $\operatorname{EME}(\mathrm{F}(3,9)=16.700$, $p=0.0001)$, and BZE plasma levels $(\mathrm{F}(3,9)=4.824$, $p=0.0108$ ), with no differences between the two phases. Table 2 shows cocaine and metabolite plasma levels $4 \mathrm{~min}$ after the last cocaine dose in females and males as a function of cocaine dose collapsed across phase, since there were no significant phase effects. With respect to sex differences, there were no differences between females and males in cocaine or EME plasma levels. However, females had higher BZE plasma levels than males following repeated doses of $25 \mathrm{mg}$ cocaine (sex $\times$ dose interaction; $\mathrm{F}(1,3)=2.899, p=0.0499$ ).

\section{DISCUSSION}

To our knowledge, this is the first study to comprehensively assess the effects of oral micronized progesterone on the response to several doses of smoked cocaine in humans. The most striking finding was that acute administration of oral micronized progesterone that resulted in physiological levels produced substantial decreases in the positive subjective effects of cocaine in females, but not in males. Further, oral micronized progesterone decreased the cocaine-induced increases in diastolic pressure and heart rate in both females and males. Lastly, there was no evidence that the effects of oral micronized progesterone were due to alterations in the pharmacokinetics of cocaine or its metabolites.

\section{Subjective Effects}

Cocaine administration produced dose-related increases in several positive subjective ratings, including the good drug effect cluster, the drug quality cluster, and 'willing to pay' item in both males and females. Further, in females these 

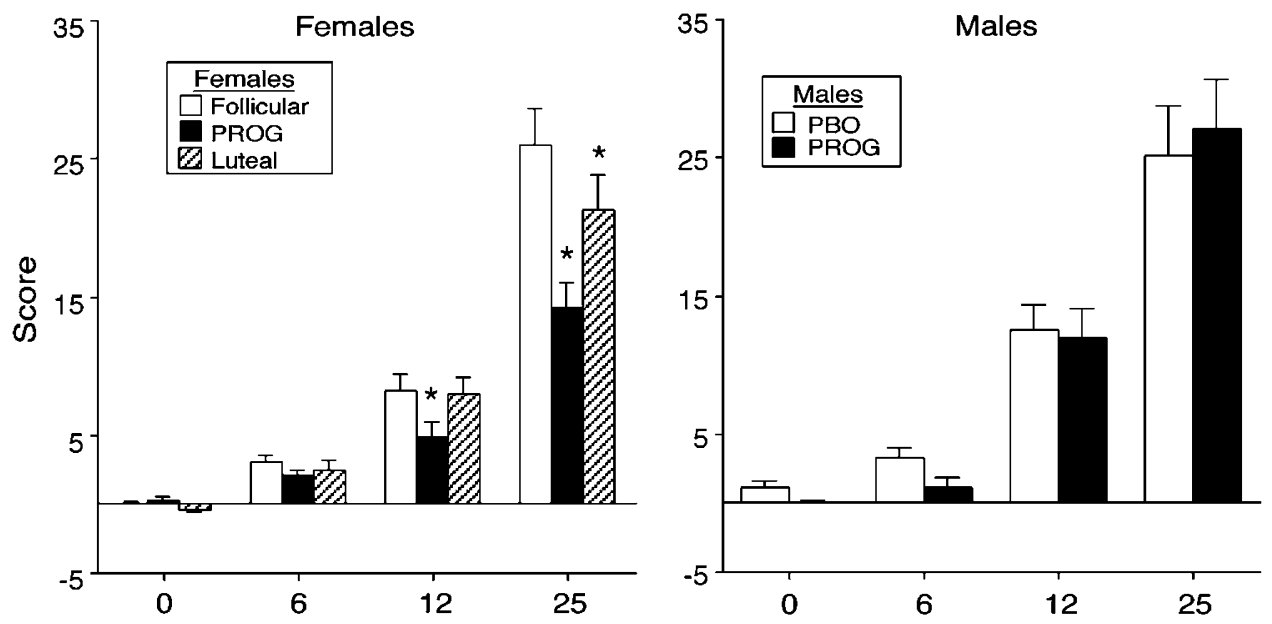

Drug Quality Cluster
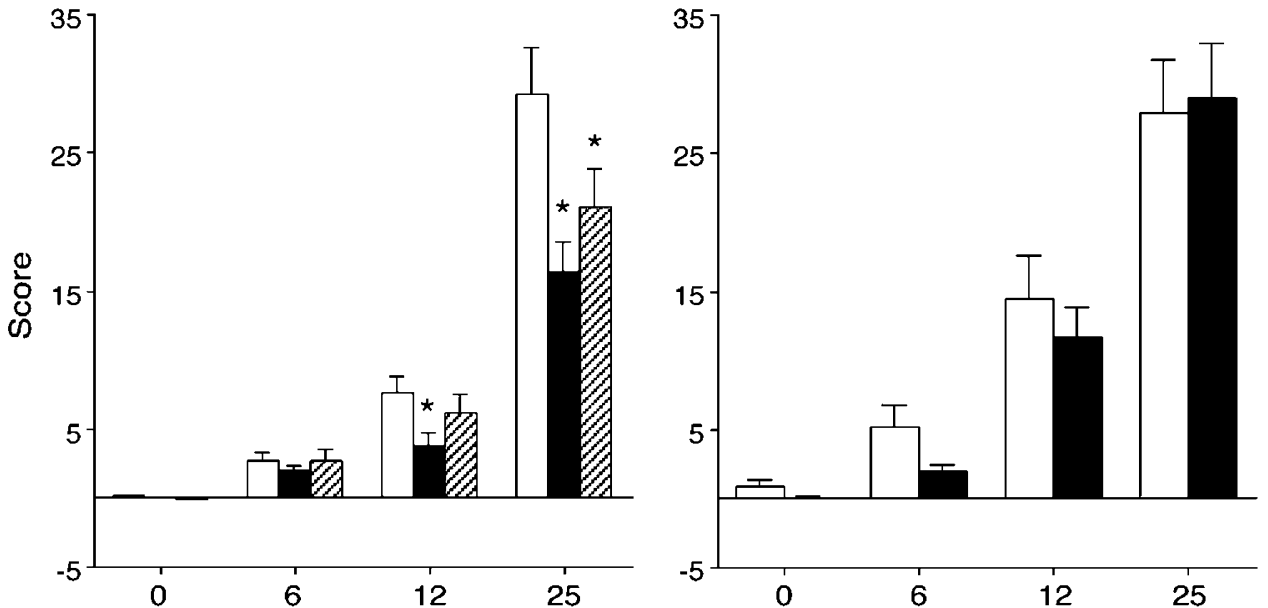

Willing to Pay
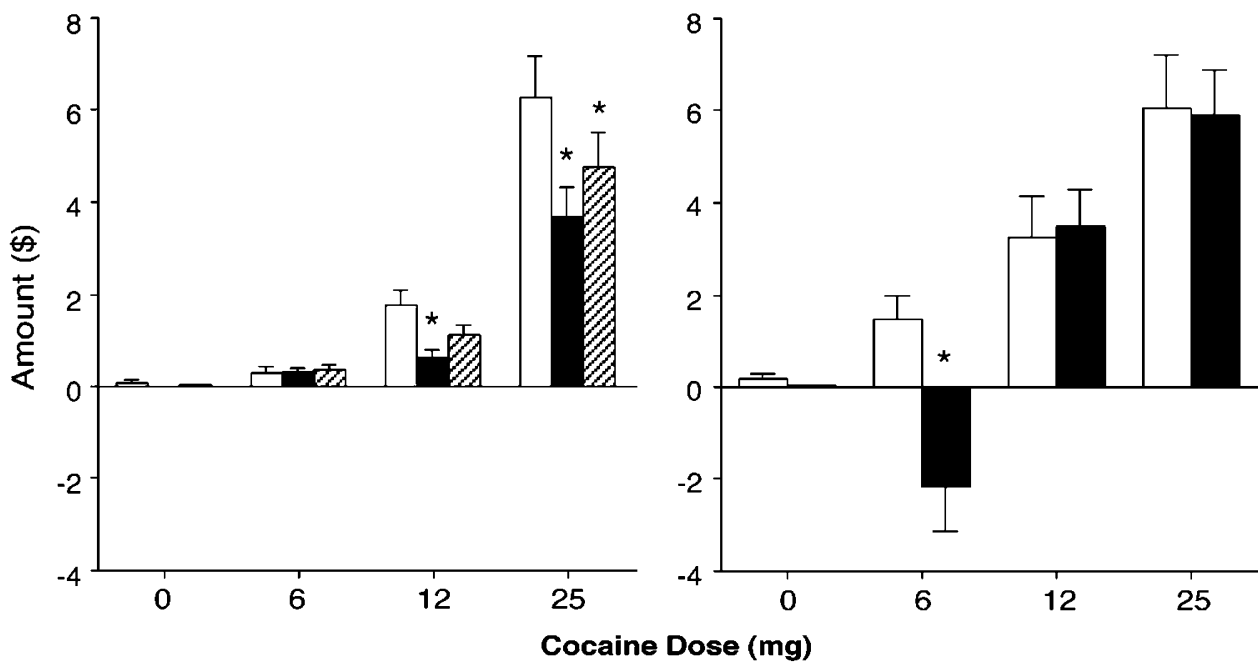

Figure 4 Mean scores of the good drug effect and drug quality clusters and 'willing to pay' ratings (expressed as change from baseline) as a function of phase and cocaine dose. * Indicates a significant difference from the follicular phase in females or a significant difference from the PBO phase in males at a given cocaine dose condition. See Figures I and 2 for details.

ratings were significantly higher in the normal follicular phase compared to the luteal phase. These results replicate previous findings in humans that the positive subjective effects of cocaine (Evans et al, 2002; Sofuoglu et al, 1999) and amphetamine (Justice and de Wit, 1999) are greater in the follicular phase compared to the luteal phase. However, 

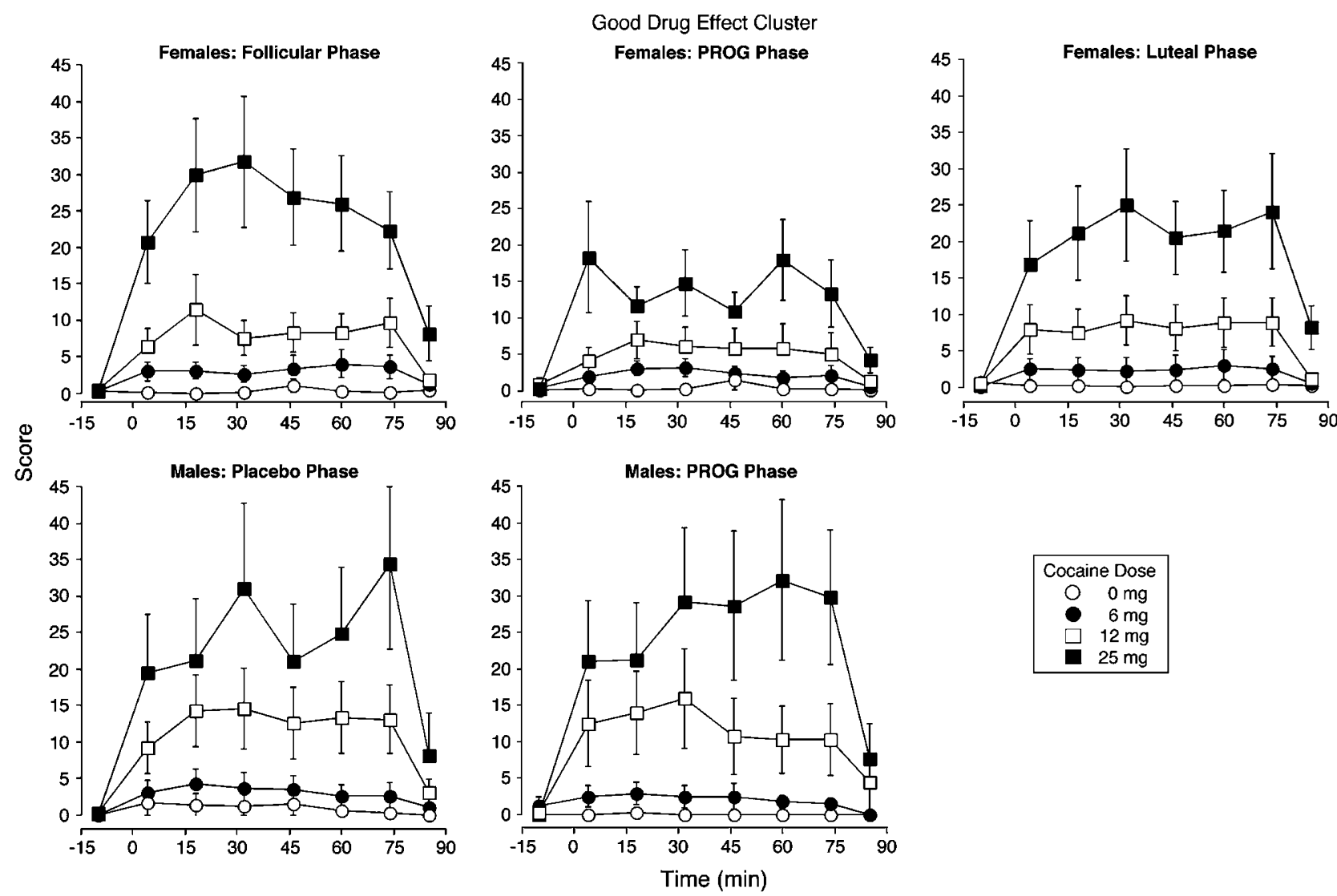

Figure 5 Time course function for good drug effect cluster scores as a function of phase and cocaine dose. For females, data from each of the three phases are presented in the top panels and each data point represents the mean \pm I SEM. For males, data from each of the two phases are presented in the bottom panels and each data point represents the mean \pm I SEM.

Table 2 Comparison of Cocaine and Metabolite Plasma Levels as a Function Cocaine Dose Administered and Sex

\begin{tabular}{|c|c|c|}
\hline & Females & Males \\
\hline \multicolumn{3}{|c|}{ Cocaine levels $(\mathrm{ng} / \mathrm{m} /)^{\mathrm{a}}$} \\
\hline $0 \mathrm{mg}$ & II.I $( \pm 2.5)$ & $5.8( \pm 3.2)$ \\
\hline $6 \mathrm{mg}$ & $107.1( \pm 8.2)$ & $106.9( \pm 9.3)$ \\
\hline $12 \mathrm{mg}$ & $222.2( \pm 11.8)$ & $214.5( \pm 14.5)$ \\
\hline $25 \mathrm{mg}$ & $455.2( \pm 24.9)$ & $455.3( \pm 39.0)$ \\
\hline
\end{tabular}

$\begin{array}{lrr}\text { EME levels }(\mathrm{ng} / \mathrm{ml}) & \\ 0 \mathrm{mg} & 8.5( \pm 2.0) & 6.8( \pm 2.9) \\ 6 \mathrm{mg} & 16.5( \pm 2.2) & 23.3( \pm 4.9) \\ 12 \mathrm{mg} & 24.1( \pm 1.7) & 26.7( \pm 3.5) \\ 25 \mathrm{mg} & 48.2( \pm 2.6) & 50.8( \pm 5.2)\end{array}$

\begin{tabular}{lll} 
BZE levels $(\mathrm{ng} / \mathrm{ml})$ & & \\
$0 \mathrm{mg}$ & $204.5( \pm 32.4)$ & $173.2( \pm 45.6)$ \\
$6 \mathrm{mg}$ & $295.7( \pm 24.8)$ & $313.7( \pm 54.2)$ \\
$12 \mathrm{mg}$ & $373.3( \pm 42.1)$ & $311.0( \pm 40.0)$ \\
$25 \mathrm{mg} * *$ & $629.5( \pm 35.8)$ & $424.0( \pm 31.2)$ \\
\hline
\end{tabular}

${ }^{a} V a l u e s$ represent the mean and \pm I SEM collapsed across phase (three phases for females and two phases for males) obtained $4 \mathrm{~min}$ after the last cocaine dose each session.

***ignificant difference between females and males. it should be noted that not all studies have shown differences in the subjective response to cocaine across the menstrual cycle (Lukas et al, 1996; Mendelson et al, 1999). In the study by Lukas et al (1996), although a range of subjective questions were measured, only a single dose of intranasal cocaine was administered. In the study by Mendelson et al (1999), separate groups of women were administered a single dose of either 0.2 or $0.4 \mathrm{mg} / \mathrm{kg}$ intravenous cocaine and only a single subjective question (ratings of 'high') was asked. At this time, it is difficult to reconcile inconsistencies among the studies that have assessed the effects of cocaine in humans across the menstrual cycle due to differences across studies with respect to the route of cocaine administration, the range of doses tested, and the number of doses administered (ie single $v s$ repeated doses), the range of subjective measures, and the use of within- $v s$ between-subjects designs.

Despite the fact that human females appear to exhibit differences in their subjective response to stimulants across the menstrual cycle, based on a limited number of controlled studies in humans, sex differences in response to cocaine are minimal (Kosten et al, 1996; Lukas et al, 1996; Haney et al, 1998; Evans et al, 1999; Mendelson et al, 1999; Sofuoglu et al, 1999). In fact, in the present study, the magnitude of positive subjective response to cocaine in females during the follicular phase was virtually identical to that of males (in the placebo phase), despite the fact that females had significantly higher estradiol levels. Consistent 
with the present findings, two other studies in humans have shown that females in the follicular phase report positive subjective effects following cocaine or amphetamine that are not different from males (Sofuoglu et al, 1999; White et al, 2002); the differences between males and females have been noted during the luteal phase in females, when progesterone levels are elevated.

In the present study, administration of oral micronized progesterone during the follicular phase substantially (by approximately $40-46 \%$ ) attenuated the positive subjective effects (eg good drug effect cluster scores, drug quality cluster scores, ratings of 'willing to pay') of cocaine in females relative to their normal luteal phase. Interestingly, this attenuation was not observed in males even though they were administered the same doses of progesterone that resulted in similar progesterone plasma levels. These results partially confirm the initial findings by Sofuoglu et al (2002, 2004), showing that progesterone attenuated the subjective effects of cocaine. Although similar doses of smoked cocaine were used in the present study $(25 \mathrm{mg})$ and the study by Sofuoglu et al (2002; $28 \mathrm{mg}$ for a $70 \mathrm{~kg}$ person), the overall magnitude of this attenuation was greater in the present study, even though the lower dose of progesterone $(150 \mathrm{mg})$ administered produced lower plasma levels of progesterone. This may be due to a number of reasons, including the increased number of cocaine doses administered (six $v s$ three doses), the shorter interval between doses (14 vs $30 \mathrm{~min}$ ), the wider range of subjective measures, and the larger sample size (11 vs five females) in the present study. Also, in contrast to the robust sex differences observed in the present study regarding progesterone's ability to attenuate the subjective effects of cocaine, Sofuoglu et al (2004) did not find any differences between males and females in subjective response, despite the fact that a higher dose of progesterone $(200 \mathrm{mg})$ was administered that resulted in higher progesterone levels than in the present study. However, there were a number of differences between the present study and the study by Sofuoglu et al (2004). Similar to participants in the present study, all participants currently smoked cocaine, but in the Sofuoglu et al (2004) study cocaine was given intravenously. Also, they used a self-administration procedure and, under those conditions, individuals only self-administered approximately half (2.5) out of the possible five doses of $0.3 \mathrm{mg} /$ $\mathrm{kg}$ i.v. cocaine (approximately $21 \mathrm{mg}$ smoked cocaine); so, essentially less cocaine was administered over the session compared to the present study that administered six $25 \mathrm{mg}$ smoked cocaine doses. Another important factor is that the study by Sofuoglu et al (2004) had a smaller sample size (six males and four females) compared to the present study (10 males and 11 females). Lastly, we tested a range of doses, while they tested only one dose and we also tested women during their normal luteal phase. Thus, the present study provides the clearest demonstration that oral micronized progesterone attenuates the subjective response to cocaine in females, but not in males.

There are a number of possible mechanisms for progesterone's attenuation of the subjective effects of cocaine, all of which are speculative at this time. The decrease in subjective response may be partially attributed to the sedative or anxiolytic effects of progesterone, primarily due to the metabolite allopregnanolone, which is thought to potentiate $\mathrm{GABA}_{\mathrm{A}}$ receptor function (Paul and Purdy, 1992; Bitran et al, 1993). In support of this, a recent study in progesterone receptor knockout mice indicated that the anxiolytic effects of progesterone did not require progesterone receptors (Reddy et al, 2005). Alternatively, progesterone may exert its activity by interacting directly with the dopamine system, although the direction of the effects of progesterone on the dopaminergic system has been inconsistent. While some laboratory studies in rats have shown that progesterone has an inhibitory effect on the dopamine system (Michanek and Meyerson, 1982; Shimizu and Bray, 1993), other studies indicate that progesterone, like estrogen, stimulates dopamine release in the striatum of both male and female rats (Petitclerc et al, 1995). A series of studies by Dluzen and Ramirez (1987, 1989, 1990a) present a more complicated picture, in that progesterone can either inhibit or enhance dopamine release, depending on the dose or whether progesterone is administered in a pulsatile or continuous infusion. Further, there is evidence that estrogen may be required for the induction of progesterone effects on the monoamine system (Dluzen and Ramirez, 1990b; Shimizu and Bray, 1993). For instance, in one study (Dluzen and Ramirez, 1990b), an infusion of progesterone only increased amphetaminestimulated dopamine release in castrated male rats treated with estrogen, but not in intact or nonestrogen-treated males. Some studies show that the effects of progesterone on dopamine are independent of estrogen (Petitclerc et al, 1995). Given that both estrogen and progesterone (under certain conditions) appear to enhance dopamine release, the effects of progesterone on the GABA system may more readily explain the attenuation in the subjective effects of cocaine.

The most common reported side effects of oral micronized progesterone administration are dizziness and sedation (Simon et al, 1993; see review by de Lignieres, 1999). Most studies that have administered oral progesterone to females report transient increases in sedation and modest performance impairment. For example, one study administered acute oral doses of up to $1200 \mathrm{mg}$ progesterone to females and reported increases in fatigue following doses of $300 \mathrm{mg}$ and higher (Freeman et al, 1992). Two more recent studies administered progesterone intramuscularly in acute doses of $100 \mathrm{mg}$ (de Wit et al, 2001) and $200 \mathrm{mg}$ (Söderpalm et al, 2004), producing peak plasma progesterone levels (82 and $175 \mathrm{ng} / \mathrm{ml}$, respectively) well above those observed during a normal luteal phase; even under those conditions there were only modest increases in sedation and minimal performance impairment. In males, oral progesterone administration ( $10 \mathrm{mg} /$ day) for 7 days impaired reaction time and increased sluggishness (Little et al, 1974), whereas an acute dose of $300 \mathrm{mg}$ did not alter cognitive performance (Grön et al, 1997). In the present study, items related to sedation were included in the bad drug effect cluster; yet, there was no evidence that progesterone administration resulted in any adverse effects.

Clinically, oral micronized progesterone is used for hormone replacement therapy (often in conjunction with estrogens) in postmenopausal women, for a variety of bleeding disorders, as well as for secondary amenorrhea (Shangold et al, 1991; de Lignieres, 1999; Fitzpatrick and Good, 1999). For these conditions, the standard dose is 
typically $100-300 \mathrm{mg} /$ day for a period of several days up to 2 weeks each menstrual cycle. In the present study, oral micronized progesterone was only administered as five $150 \mathrm{mg}$ doses over a $36-\mathrm{h}$ period. Previous studies have indicated that the pharmacokinetics of oral micronized progesterone can be quite variable (Freeman et al, 1993; Maxson and Hargrove, 1985). Fortunately, in the present study the dosing regimen of micronized progesterone administered to females in the follicular phase resulted in comparable levels compared to their normal midluteal phase and produced similar progesterone levels in men (cf. Figure 1). Further, there were no differences in progesterone levels as a function of day or time (cf. Table 1). This was critical since the purpose was to determine the effects of physiological levels of exogenous progesterone comparable to the normal midluteal phase on the response to cocaine. We gave an oral dose of $150 \mathrm{mg}$ micronized progesterone the evening before the first cocaine session because steadystate plasma levels are achieved after the second dose (see review by de Lignieres, 1999). Also, our progesterone doses were custom-made, allowing us to administer $150 \mathrm{mg}$ micronized progesterone, rather than the commercially available 100 or $200 \mathrm{mg}$ doses.

\section{Cardiovascular Effects}

Only heart rate showed any differences at baseline, with females having significantly higher resting heart rate in the luteal phase compared to the follicular phase. This finding is consistent with other studies that have measured cardiovascular functioning during the menstrual cycle in women (eg Moran et al, 2000; Manhem and Jern, 1994; Lukas et al, 1996; Evans et al, 2002). Further, progesterone administration increased baseline heart rate in females to levels seen in the normal luteal phase and these levels were higher than levels observed in males during the PROG phase. While a recent study (Söderpalm et al, 2004) also showed that progesterone increased heart rate in women, but not in men, other studies have not shown that progesterone administration increases heart rate in females (Sofuoglu et al, 2002, 2004) or males (Sofuoglu et al, 2004). Similar to clinical studies (see review by de Lignieres, 1999), there was no evidence that progesterone altered baseline blood pressure.

In the present study, cocaine produced greater increases in diastolic pressure in the luteal phase compared to the follicular phase, but there were no differences in systolic pressure or heart rate between the luteal and follicular phases. While these results confirm our previous study (Evans et al, 2002), several previous studies have not observed any differences in cocaine-induced increases in blood pressure or heart rate between the follicular and luteal phases of the menstrual cycle (Lukas et al, 1996; Mendelson et al, 1999; Sofuoglu et al, 1999). Possible differences across these studies could include the various routes of cocaine administered, the use of relatively small sample sizes, and the use of between-subject designs (Mendelson et al, 1999; Sofuoglu et al, 1999). In the present study, there was suggestive evidence that males had an enhanced cardiovascular response to cocaine compared to females, although this did not reach statistical significance. Previous studies have shown minimal cardiovascular differences in response to cocaine administration between males and females (Lukas et al, 1996; Mendelson et al, 1999; Sofuoglu et al, 1999; Evans et al, 1999).

Interestingly, progesterone administration attenuated the cocaine-induced increases in diastolic pressure and heart rate following repeated doses of $25 \mathrm{mg}$ smoked cocaine in both females and males in the present study. At this time, only two other studies have administered progesterone and cocaine to humans and the cardiovascular results have been inconsistent. In one study (Sofuoglu et al, 2002), there were no changes in heart rate or blood pressure when progesterone was administered to females in the follicular phase. However, in a subsequent study by the same group (Sofuoglu et al, 2004), progesterone administration attenuated the cocaine-induced increases in diastolic pressure (but not systolic pressure or heart rate) and this effect was observed in males, but not in females. The mechanism for the attenuation of the cocaine-induced increases in heart rate and diastolic blood pressure by oral micronized progesterone is unclear. In fact, the available literature regarding the effects of progesterone on the cardiovascular system is complex. Progesterone has been shown to decrease blood pressure in ewes (Pecins-Thompson and Keller-Wood, 1997), as well as in normotensive and hypertensive rats (Liao et al, 1996; Eikelis and van den Buuse, 2000). The results in humans are also inconsistent. This is in part related to whether progesterone was administered alone, or in combination with estrogen, and the actual formulation of progesterone. For instance, studies that use synthetic progestins, such as medroxyprogesterone acetate, do not appear to demonstrate any cardiovascular benefit, and may actually attenuate the beneficial effects of estrogen therapy (eg Manson et al, 2003; Matthews et al, 2005). In contrast, studies that use natural micronized progesterone derived from plant sources have either shown no effect on heart rate or blood pressure (Honisett et al, 2003), or have shown that it decreases the cardiovascular response to stress when combined with an estrogen (Matthews et al, 2005). The effect of progesterone on the response to cocaine is even less clear. Some studies in pregnant sheep (Woods and Plessinger, 1990) or nonpregnant sheep treated with levels of progesterone observed during pregnancy (Plessinger and Woods, 1990) show an enhanced hypertensive response to cocaine. Similarly, studies using isolated papillary heart muscles from pregnant or progesterone-treated rats indicate that the cardiotoxicity to cocaine is increased, in part due to progesterone (Sharma et al, 1992), since this effect is attenuated by the progesterone antagonist mifepristone (Sharma et al, 1993). Of course, the levels of progesterone attained in these studies mimicked those observed during pregnancy. In human females, progesterone levels during pregnancy are 5-8 times higher than during the normal luteal phase.

At this time it is also unclear why oral progesterone attenuated the cardiovascular effects of cocaine, but not the subjective effects of cocaine, in men. Interestingly, while not statistically significant, the reduction in heart rate and blood pressure in men was not as robust as in women. Since only one 'dose' of progesterone was tested, it is unknown whether higher doses of progesterone would attenuate these cocaine-induced effects in men. In one study, natural progesterone administration $(200,400$, and $600 \mathrm{mg} /$ day $)$ for 
2 weeks reduced blood pressure in both hypertensive males and females (Rylance et al, 1985), although, in another study, administration of $400 \mathrm{mg} /$ day natural progesterone to males for 10 days did not alter blood pressure (Tollan et al, 1993). Some studies suggest that the cardiovascular effects of progesterone are peripherally mediated (Tollan et al, 1993), whereas the subjective effects are presumably centrally mediated. Taken together, additional research is needed to determine the cardiovascular response to oral micronized progesterone at normal physiologic levels, alone, and in combination with cocaine.

\section{Cocaine and Metabolite Levels}

In the present study, there were no differences in cocaine plasma levels as a function of menstrual cycle phase or progesterone administration in females and males. Further, there were no sex differences in cocaine plasma levels. Previous studies in humans have also failed to demonstrate differences in cocaine plasma levels across the menstrual cycle (Sofuoglu et al, 1999; Evans et al, 2002) or between males and females (Kosten et al, 1996; Sofuoglu et al, 1999; Mendelson et al, 1999). In a previous study (Evans et al, 1999), we reported that females had higher cocaine plasma levels than males after smoking six doses of $50 \mathrm{mg}$ cocaine, but this was most likely due to the fact that the females weighed less than the males, which was not the case in the present study.

The cocaine metabolites EME and BZE were also measured in the present study. As with cocaine, there were no differences in EME plasma levels as a function of menstrual cycle phase, progesterone administration, or sex. While BZE plasma levels also did not differ as a function of menstrual cycle phase or progesterone administration, females had significantly higher BZE plasma levels following $25 \mathrm{mg}$ cocaine than males. These findings contrast with our previous study (Evans et al, 1999) that failed to show differences in BZE levels between males and females despite differences in cocaine levels; the reasons for these discrepancies are unclear. A clear limitation of the present study is that blood samples for cocaine and metabolite levels were not collected multiple times after the last dose of cocaine each session. Unfortunately, in the elegant cocaine pharmacokinetic study by Mendelson et al (1999), cocaine metabolite levels were not reported. However, studies in laboratory animals, including rats (Bowman et al, 1999) and rhesus monkeys, have also failed to show differences in cocaine plasma levels as a function of sex (Mello et al, 2002) or menstrual cycle phase (Mello et al, 2000; Evans and Foltin, 2004). In the one study that reported cocaine metabolite levels, BZE and EME plasma levels showed the greatest increases in the luteal phase compared to the other phases following the highest dose of cocaine (Evans and Foltin, 2004). Therefore, based on the limited data available in both monkeys and humans, there appear to be minimal differences in the pharmacokinetics of cocaine across the menstrual cycle or between males and females.

\section{Comparisons between Laboratory Animals and Humans}

The majority of research in laboratory animals (primarily rats) has focused on the role of estrogen as a primary contributor to the sex differences observed in the behavioral response to stimulants (see reviews by Lynch et al, 2002; Mello and Mendelson, 2002; Carroll et al, 2004; Festa and Quiñones-Jenab, 2004). The modulatory role of estradiol and progesterone may also depend on the specific behavior measured. Numerous studies in rats have shown that estrogen enhances sensitization to behaviors such as rotational behavior (eg $\mathrm{Hu}$ and Becker, 2003) and locomotor activity (see the review by Festa and Quiñones-Jenab, 2004), and that estrogen may modulate self-administration (see the review by Carroll et al, 2004). However, some studies have failed to show either sex differences or enhancement from estradiol on cocaine self-administration (Caine et al, 2004), while other studies have failed to show sex differences in cocaine drug discrimination studies (Craft and Stratmann, 1996; Anderson and van Haaren, 1999, 2000). As mentioned previously, in human females, the subjective response to stimulants is greater during the follicular phase compared to the luteal phase (Sofuoglu et al, 1999; White et al, 2002; Evans et al, 2002), which, in conjunction with the rodent literature, has been most commonly interpreted to indicate that estradiol enhances the effects of stimulants and accounts for any differences observed between males and females. However, the present study and other studies in humans (Sofuoglu et al, 1999; White et al, 2002) have shown that females in the follicular phase (when estradiol is elevated and progesterone is minimal) report similar increases in positive subjective effects to stimulants compared to males, whereas the sex differences have been observed only when females are in the luteal phase, when both progesterone and estradiol levels are elevated. These findings suggest that progesterone, rather than estradiol, may play an important role in modulating the response to stimulants in human females.

Relatively few laboratory animal studies have assessed the effects of progesterone, either alone or in combination with estrogen, and the results have been inconsistent (see the review by Festa and Quiñones-Jenab, 2004). For instance, progesterone replacement in ovariectomized rats has been shown to not alter cocaine-induced locomotor activity (Perotti et al, 2001; Quiñones-Jenab et al, 2000; Sircar and Kim, 1999), but it did inhibit cocaine-induced conditioned place preference (Russo et al, 2003). Interestingly, coadministration of estrogen and progesterone appears to potentiate cocaine-induced behaviors in ovariectomized female rats (Quiñones-Jenab et al, 2000; Sell et al, 2000; Sircar and Kim, 1999; Russo et al, 2003). In a recent study (Niyomchai et al, 2005), the effects of progesterone administration on cocaine-induced rearing in ovariectomized female rats appeared to depend on dose, with intermediate doses enhancing cocaine-induced rearing and low or high doses attenuating cocaine-induced rearing. Unfortunately, none of these studies administered progesterone to intact rats and the behavioral response may depend on a complex temporal relationship between estrogen and progesterone. Taken together, these findings are somewhat inconsistent with the available human data, including the present study, and point to the importance of translational research. While the findings in rodents have enhanced our understanding regarding the influence of sex and gonadal hormones on the response to cocaine, it is unlikely that we can adequately compare the 4-day estrus cycle of a female rat to the 28-day 
menstrual cycle of a woman. For instance, in rodents many of the increases in the reinforcing effects of cocaine are observed during estrus, but this is when estradiol and progesterone levels are relatively low (Butcher et al, 1974; Smith et al, 1975). In order to more closely model the human condition, additional rodent studies are needed to address the role of progesterone in intact animals. Further, rodent studies need to confirm the estrus cycle via hormone levels where possible. Alternatively, given that female monkeys have a menstrual cycle comparable to humans, parallel studies in non-human primates should be conducted to address the modulatory role of estradiol and/or progesterone on the behavioral response to cocaine.

\section{Limitations}

One limitation of the present study is that relatively low cocaine doses were tested. This was to increase the likelihood of detecting subtle differences since findings from previous studies have shown that the subjective effects of low cocaine doses can be attenuated more readily than high cocaine doses (Haney et al, 1998, 1999; Walsh et al, 2000; Evans et al, 2002). It is possible that if higher doses of cocaine were tested (eg $50 \mathrm{mg}$ smoked cocaine), physiological levels of progesterone may not attenuate the subjective effects of cocaine. Another limitation is that participants were administered cocaine, as opposed to being allowed to self-administer cocaine. This was done so that we could adequately address whether or not progesterone would attenuate the subjective effects of cocaine, which would have been confounded if a self-administration procedure had been used. Of course, it is critical to determine if this dramatic reduction in subjective response in the presence of progesterone will translate into a reduction in actual drug-taking behavior. Several studies have reported that drugs that reduce the subjective effects of cocaine do not necessarily alter cocaine self-administration in the laboratory (Haney et al, 1998, 1999). Based on the preliminary findings of Sofuoglu et al (2004), progesterone produced small transient decreases in the subjective effects of cocaine, but did not produce a corresponding decrease in cocaine self-administration. Therefore, future studies need to administer progesterone to human cocaine abusers to determine the correspondence between alterations in the subjective response and cocaine self-administration, using a wide range of cocaine doses.

\section{Implications}

The major purpose of this study was to examine one mechanism underlying the differences in subjective response to cocaine across the menstrual cycle in humans. The present results, in conjunction with the few other studies in humans, are intriguing in that they suggest that progesterone may play a prominent role in the response to stimulants in females. Moreover, the present results suggest that these effects of progesterone are specific to females, but do not alter the response to males. Although these results need to be replicated, it is not unreasonable to assume that males and females would respond differently to gonadal hormones given that laboratory animal studies have demonstrated that intrinsic sex differences, in addition to gonadal hormones, contribute to sex differences in response to cocaine (Hu et al, 2004).

\section{ACKNOWLEDGEMENTS}

This research was supported by Grant No. DA-08105 from the National Institute on Drug Abuse. Participants resided on the Irving Center for Clinical Research of The ColumbiaPresbyterian Medical Center supported by Grant No. MOI-RR-00645 from the National Institutes of Health. The assistance of Laura Burr, RN, Mr Thomas B Cooper and Drs Eric Collins, Michel Ferin, and Robert MacArthur is gratefully acknowledged. Oral micronized progesterone and matching placebo capsules were generously provided by the Women's International Pharmacy.

\section{REFERENCES}

Anderson KG, van Haaren F (1999). Cocaine discrimination and time-course effects in male and female Wistar rats. Eur $J$ Pharmacol 382: 69-74.

Anderson KG, van Haaren F (2000). Effects of SCH-23390 and raclopride on cocaine discrimination in male and female Wistar rats. Pharmacol Biochem Behav 65: 671-675.

Becker JB, Cha J-H (1989). Estrous cycle-dependent variation in amphetamine-induced behaviors and striatal dopamine release assessed with microdialysis. Behav Brain Res 35: 117-125.

Becker JB, Robinson TE, Lorenz KA (1982). Sex differences and estrous cycle variations in amphetamine-elicited rotational behavior. Eur J Pharmacol 80: 65-72.

Bowman BP, Vaughan SR, Walker QD, Davis SL, Little PJ, Scheffler NM et al (1999). Effects of sex and gonadectomy on cocaine metabolism in the rat. J Pharmacol Exp Ther 290: 1316-1323.

Bitran D, Purdy RH, Kellogg CK (1993). Anxiolytic effect of progesterone is associated with increases in cortical allopregnanolone and $\mathrm{GABA}_{\mathrm{A}}$ receptor function. Pharm Biochem Behav 45: 423-428.

Butcher RL, Collins WE, Fugo NW (1974). Plasma concentrations of $\mathrm{LH}, \mathrm{FSH}$, prolactin, progesterone and estradiol-17 $\beta$ throughout the 4-day estrous cycle of the rat. Endocrinology 94: 1704-1708.

Caine SB, Bowen CA, Yu G, Zuzga D, Negus SS, Mello NK (2004). Effect of gonadectomy and gonadal hormone replacement on cocaine self-administration in female and male rats. Neuropsychopharmacology 29: 929-942.

Camp DM, Becker JB, Robinson TE (1986). Sex differences in the effects of gonadectomy on amphetamine-induced rotational behavior in rats. Behav Neural Biol 46: 491-495.

Carroll ME, Lynch WJ, Roth ME, Morgan AD, Cosgrove KP (2004). Sex and estrogen influence drug abuse. Trends Pharmacol Sci 25: 273-279.

Castner SA, Xiao L, Becker JB (1993). Sex differences in striatal dopamine: in vivo microdialysis and behavioral studies. Brain Res 610: 127-134.

Craft RM, Stratmann JA (1996). Discriminative stimulus effects of cocaine in female versus male rats. Drug Alcohol Depend 42: 27-37.

de Lignieres B (1999). Oral micronized progesterone. Clin Ther 21: 41-60.

de Wit H, Schmitt L, Purdy R, Hauger R (2001). Effects of acute progesterone administration in healthy postmenopausal women and normally-cycling women. Psychoneuroendocrinology 26: 697-710.

Diaz-Veliz G, Baeza R, Benavente F, Dussaubat N, Mora S (1994). Influence of the estrous cycle and estradiol on the behavioral effects of amphetamine and apomorphine in rats. Pharmacol Biochem Behav 49: 819-825. 
Dluzen DE, Ramirez VD (1987). Intermittent infusion of progesterone potentiates whereas continuous infusion reduces amphetamine-stimulated dopamine release from ovariectomized estrogen-primed rat striatal fragments superfused in vitro. Brain Res 406: 1-9.

Dluzen DE, Ramirez VD (1989). Progesterone enhances L-dopastimulated release from the caudate nucleus of freely behaving ovariectomized-estrogen-primed rats. Brain Res 494: 122-128.

Dluzen DE, Ramirez VD (1990a). In vitro progesterone modulation of amphetamine-stimulated dopamine release from the corpus striatum of ovariectomized estrogen-treated female rats: response characteristics. Brain Res 517: 117-122.

Dluzen DE, Ramirez VD (1990b). In vitro progesterone modulates amphetamine-stimulated dopamine release from the corpus striatum of castrated male rats treated with estrogen. Neuroendocrinology 52: 517-520.

Eikelis N, van den Buuse M (2000). Cardiovascular responses to open-field stress in rats: sex differences and effects of gonadal hormones. Stress 3: 319-334.

Evans SM, Foltin RW (2004). Pharmacokinetics of intravenous cocaine across the menstrual cycle in rhesus monkeys. Neuropsychopharmacology 29: 1889-1900.

Evans SM, Haney M, Fischman MW, Foltin RW (1999). Limited sex differences in response to binge smoked cocaine use in humans. Neuropsychopharmacology 21: 445-454.

Evans SM, Haney M, Foltin RW (2002). The effects of smoked cocaine during the follicular and luteal phases of the menstrual cycle in women. Psychopharmacology 159: 397-406.

Festa ED, Quiñones-Jenab V (2004). Gonadal hormones provide the biological basis for sex differences in behavioral responses to cocaine. Horm Behav 46: 509-519.

First MB, Spitzer RL, Gibbon M, Williams JBW (1994). Structured Clinical Interview for DSM-IV Axis I Disorders - Patient Edition (SCID-I/P, version 2.0). Biometrics Research Department, New York State Psychiatric Institute.

Fitzpatrick LA, Good A (1999). Micronized progesterone: clinical indications and comparison with current treatments. Fertil Steril 72: 389-397.

Foltin RW, Fischman MW, Nestadt G, Stromberger H, Cornell EE, Pearlson GD (1990). Demonstration of naturalistic methods for cocaine smoking by human volunteers. Drug Alcohol Depend 26: 145-154.

Freeman EW, Purdy RH, Coutifaris C, Rickels K, Paul SM (1993). Anxiolytic metabolites of progesterone: correlation with mood and performance measures following oral progesterone administration to healthy female volunteers. Neuroendocrinology 58: 478-484.

Freeman EW, Weinstock L, Rickels K, Sondheimer SJ, Coutifaris C (1992). A placebo-controlled study of effects of oral progesterone on performance and mood. Br J Clin Pharmacol 33: 293-298.

Grimm J, See RE (1997). Cocaine self-administration in ovariectomized rats is predicted by response to novelty, attenuated by 17-B estradiol, and associated with abnormal vaginal cytology. Physiol Behav 61: 755-761.

Grön G, Friess E, Herpers M, Rupprecht R (1997). Assessment of cognitive performance after progesterone administration in healthy male volunteers. Neuropsychobiology 35: 147-151.

Haney M, Castanon N, Cador M, Le Moal M, Mormede P (1994). Cocaine sensitivity in roman high and low avoidance rats is modulated by sex and gonadal hormone status. Brain Res 645: 179-185.

Haney M, Collins ED, Ward AS, Foltin RW, Fischman MW (1999). Effect of a selective dopamine D1 agonist (ABT-431) on smoked cocaine self-administration in humans. Psychopharmacology 143: $102-110$.

Haney M, Foltin RW, Fischman MW (1998). Effects of pergolide on intravenous cocaine self-administration in men and women. Psychopharmacology 137: 15-24.
Hecht GS, Spear NE, Spear LP (1999). Changes in progressive ratio responding for intravenous cocaine throughout the reproductive process in female rats. Dev Psychobiol 35: 136-145.

Honisett SY, Pang B, Stojanovska L, Sudhir K, Komesaroff PA (2003). Progesterone does not influence vascular function in postmenopausal women. J Hypertens 21: 1145-1149.

$\mathrm{Hu}$ M, Becker JB (2003). Effects of sex and estrogen on behavioral sensitization to cocaine in rats. J Neurosci 23: 693-699.

$\mathrm{Hu}$ M, Crombag HS, Robinson TE, Becker JB (2004). Biological basis of sex differences in the propensity to self-administer cocaine. Neuropsychopharmacology 29: 81-85.

Justice AJH, de Wit H (1999). Acute effects of $d$-amphetamine during the follicular and luteal phases of the menstrual cycle in women. Psychopharmacology 145: 67-75.

Justice $\mathrm{AJH}$, de Wit $\mathrm{H}$ (2000a). Acute effects of $d$-amphetamine during the early and late follicular phases of the menstrual cycle in women. Pharmacol Biochem Behav 66: 509-515.

Justice AJH, de Wit H (2000b). Acute effects of estradiol pretreatment on the response to $d$-amphetamine in women. Neuroendocrinology 71: 51-59.

Kosten TR, Kosten TA, McDougle CJ, Hameedi FA, McCance EF, Rosen MI et al (1996). Gender differences in response to intranasal cocaine administration to humans. Biol Psychiatry 39: 147-148.

Liao QP, Buhimschi IA, Saade G, Chwalisz K, Garfield RE (1996). Regulation of vascular adaptation during pregnancy and postpartum: effects of nitric oxide inhibition and steroid hormones. Hum Reprod 11: 2777-2784.

Little BC, Matta RJ, Zahn TP (1974). Physiological and psychological effects of progesterone in man. J Nerv Ment Dis 159: 256-262.

Lukas SE, Sholar M, Hundahl LH, Lamas X, Kouri E, Wines JD et al (1996). Sex differences in plasma cocaine levels and subjective effects after acute cocaine administration in human volunteers. Psychopharmacology 125: 346-354.

Lynch WJ, Arizzi MN, Carroll ME (2000). Effects of sex and the estrous cycle on regulation of intravenously self-administered cocaine in rats. Psychopharmacology 152: 132-139.

Lynch WJ, Roth ME, Mickelberg JL, Carroll ME (2001). Role of estrogen in the acquisition of intravenously self-administered cocaine in female rats. Pharmacol Biochem Behav 68: 641-646.

Lynch WJ, Roth MN, Carroll ME (2002). Biological basis of sex differences in drug abuse: preclinical and clinical studies. Psychopharmacology 164: 121-137.

Manhem K, Jern S (1994). Influence of daily-life activation on pulse rate and blood pressure changes during the menstrual cycle. J Hum Hypertens 8: 851-856.

Manson JE, Hsia J, Johnson KC, Rossouw JE, Assaf AR, Lasser NL, et al, Women's Health Initiative Investigators (2003). Estrogen plus progestin and the risk of coronary heart disease. $N$ Engl $J$ Med 349: 523-534.

Martini MC, Lampe JW, Slavin JL, Kurzer MS (1994). Effect of the menstrual cycle on energy and nutrient intake. Am J Clin Nutr 60: 895-899.

Matthews KA, Owens JF, Salomon K, Harris KF, Berga SL (2005). Influence of hormone therapy on the cardiovascular responses to stress of postmenopausal women. Biol Psychol 69: 39-56.

Maxson WS, Hargrove JT (1985). Bioavailability of oral micronized progesterone. Fertil Steril 44: 622-626.

Mello NK, Bowen CA, Mendelson JH (2002). Comparison of plasma cocaine levels during a 'binge' pattern of cocaine administration in male and female rhesus monkeys. Psychopharmacology 164: 19-26.

Mello NK, Mendelson JH (2002). Cocaine, hormones, and behavior: clinical and preclinical studies. Hormones Brain Behav 5: 665-745.

Mello NK, Mendelson JH, Kelly M, Bowen C (2000). The effects of cocaine on basal and human chorionic gonadotropin-stimulated ovarian steroid hormones in female rhesus monkeys. J Pharmacol Exp Ther 294: 1137-1145. 
Mendelson JH, Mello NK, Sholar MB, Siegel AJ, Kaufman MJ, Levin $\mathrm{JM}$ et al (1999). Cocaine pharmacokinetics in men and in women during the follicular and luteal phases of the menstrual cycle. Neuropsychopharmacology 21: 294-303.

Michanek A, Meyerson BJ (1982). Influence of estrogen and progesterone on behavioral effects of apomorphine and amphetamine. Pharmacol Biochem Behav 16: 875-879.

Moran VH, Leathard HL, Coley J (2000). Cardiovascular functioning during the menstrual cycle. Clin Physiol 20: 496-504.

Niyomchai T, Russo SJ, Festa ED, Akhavan A, Jenab S, QuiñonesJenab V (2005). Progesterone inhibits behavioral responses and estrogen increases corticosterone levels after acute cocaine administration. Pharmacol Biochem Behav 80: 603-610.

Paul SM, Purdy RH (1992). Neuroactive steroids. FASEB J 6: 2311-2322.

Pecins-Thompson M, Keller-Wood M (1997). Effects of progesterone on blood pressure, plasma volume, and responses to hypotension. Am J Physiol 272: 377-385.

Perotti LI, Russo SJ, Fletcher H, Chin J, Webb T, Jenab S et al (2001). Ovarian hormones modulate cocaine-induced locomotor and stereotypic activity. Ann NY Acad Sci 937: 202-216.

Petitclerc M, Bedard PJ, DiPaolo T (1995). Progesterone releases dopamine in male and female rat striatum: a behavioral and microdialysis study. Prog Neuro-Psychopharm Behav Psychiatry 19: 491-497.

Plessinger MA, Woods Jr JR (1990). Progesterone increases cardiovascular toxicity to cocaine in nonpregnant ewes. $A m \mathrm{~J}$ Obstet Gynecol 163: 1659-1664.

Quiñones-Jenab V, Ho A, Schlussman SD, Franck J, Kreek MJ (1999). Estrous cycle differences in cocaine-induced stereotypic and locomotor behaviors in Fischer rats. Behav Brain Res 101: $15-20$.

Quiñones-Jenab V, Perrotti LI, Mc Monagle J, Ho A, Kreek MJ (2000). Ovarian hormone replacement affects cocaine-induced behaviors in ovariectomized female rats. Pharmacol Biochem Behav 67: 417-422.

Reddy DS, O’Malley BW, Rogawski MA (2005). Anxiolytic activity of progesterone in progesterone receptor knockout mice. Neuropharmacology 48: 14-24.

Roberts DCS, Bennett SAL, Vickers GJ (1989). The estrous cycle affects cocaine self-administration on a progressive ratio schedule in rats. Psychopharmacology 98: 408-411.

Roberts DCS, Dalton JCH, Vickers GJ (1987). Increased selfadministration of cocaine following haloperidol: effect of ovariectomy, estrogen replacement, and estrous cycle. Pharmacol Biochem Behav 26: 37-43.

Russo SJ, Festa ED, Fabian SJ, Gazi FM, Kraisch M, Jenab S et al (2003). Gonadal hormones differentially modulate cocaineinduced place preference in male and female rats. Neuroscience 120: $523-533$.

Rylance PB, Brincat M, Lafferty K, de Trafford JC, Brincat S, Parsons $\mathrm{V}$ et al (1985). Natural progesterone and antihypertensive action. $\mathrm{Br} \mathrm{Med} J$ 290: 13-14.

Sell SL, Scalzitti JM, Thomas ML, Cunningham KA (2000). Influence of ovarian hormones and estrous cycle on the behavioral responses to cocaine in female rats. J Pharmacol Exp Ther 293: 879-886.

Shangold MM, Tomai TP, Cook JD, Jacobs SL, Zinaman MJ, Chin SY et al (1991). Factors associated with withdrawal bleeding after administration of oral micronized progesterone in women with secondary amenorrhea. Fertil Steril 56: 1040-1047.

Sharma A, Plessinger MA, Miller RK, Woods Jr JR (1993). Progesterone antagonist mifepristone (RU 486) decreases cardiotoxicity of cocaine. Proc Soc Exp Biol Med 202: 279-287.

Sharma A, Plessinger MA, Sherer DM, Liang C-S, Miller RK, Woods Jr JR (1992). Pregnancy enhances cardiotoxicity of cocaine: role of progesterone. Toxicol Appl Pharmacol 113: 30-35.

Shimizu H, Bray GA (1993). Effects of castration, estrogen replacement and estrus cycle on monoamine metabolism in the nucleus accumbens, measured by microdialysis. Brain Res 621: 200-206.

Simon JA, Robinson DE, Andrews MC, Hildebrand III JR, Rocci Jr ML, Blake RE et al (1993). The absorption of oral micronized progesterone: the effect of food, dose proportionality, and comparison with intramuscular progesterone. Fertil Steril 60: 26-33.

Sircar R, Kim D (1999). Female gonadal hormones differentially modulate cocaine-induced behavioral sensitization in Fischer, Lewis, and Sprague-Dawley rats. J Pharmacol Exp Ther 289: 54-65.

Smith MS, Freeman ME, Neill JD (1975). The control of progesterone secretion during the estrous cycle and early pseudopregnancy in the rat: prolactin, gondadotropin and steroid levels associated with rescue of the corpus luteum of pseudopregnancy. Neuroendocrinology 96: 219-226.

Söderpalm AH, Lindsey S, Purdy RH, Hauger R, de Wit H (2004). Administration of progesterone produces mild sedative-like effects in men and women. Psychoneuroendocrinology 29: 339-354.

Sofuoglu M, Babb DA, Hatsukami DK (2002). Effects of progesterone treatment on smoked cocaine response in women. Pharmacol Biochem Behav 72: 431-435.

Sofuoglu M, Dudish-Poulsen S, Nelson D, Pentel PR, Hatsukami DK (1999). Sex and menstrual cycle differences in the subjective effects from smoked cocaine in humans. Exp Clin Psychopharmacol 7: 274-283.

Sofuoglu M, Mitchell E, Kosten TR (2004). Effects of progesterone treatment on cocaine responses in male and female cocaine users. Pharmacol Biochem Behav 78: 699-705.

Tollan A, Oian P, Kjeldsen SE, Eide I, Maltau JM (1993). Progesterone reduces sympathetic tone without changing blood pressure or fluid balance in men. Gynecol Obstet Invest 36: 234-238.

Walsh SL, Haberny KA, Bigelow GE (2000). Modulation of the effects of intravenous cocaine following chronic oral cocaine in humans. Psychopharmacology 150: 361-373.

White TL, Justice AJ, de Wit H (2002). Differential subjective effects of D-amphetamine by gender, hormone levels and menstrual cycle phase. Pharmacol Biochem Behav 73: 729-741.

Woods Jr JR, Plessinger MA (1990). Pregnancy increases cardiovascular toxicity to cocaine. Am J Obstet Gynecol 162: 529-533. 